\title{
Thioredoxin system - a novel therapeutic target
}

\author{
Michaela Koháryová and Marta Kollárová \\ Faculty of Natural Sciences, Comenius University, Department of Biochemistry, Mlynská dolina, 842 15, Bratislava, Slovak \\ Republic
}

\begin{abstract}
Nowadays there are numerous pathogens that have created a resistance to commonly used antibiotics and drugs. Therefore research is focused on finding new therapeutic targets and on determination of their 3D structures that could help in designing new effective substances and inhibitors. Thioredoxin system not only plays a crucial role as thiol/disulfide redox controller, it is also essential for certain organisms as the only system ensuring the redox homeostasis. It is the redox-regulating function, which makes thioredoxin and thioredoxin reductase attractive for scientific research, especially in many studies of diseases caused by redox instability. Thanks to these facts, the proteins of thioredoxin system are suitable candidates for new therapeutic purposes. In this review we summarized the basic features of the thioredoxin system, we justified why the proteins of thioredoxin system are appropriate therapeutical targets and we provided overview of the possibilities of their inhibition by several types of inhibitors.
\end{abstract}

Key words: Thioredoxin system - Inhibitors - Oxidative stress

\section{Thioredoxin system}

Thioredoxin system (Trx system) was identified in organisms at all levels of evolution - from archaea to man. It is composed of proteins belonging to the oxidoreductase family: thioredoxin ( $\operatorname{Trx})$, an enzyme thioredoxin reductase (TrxR) and NADPH coenzyme. TrxR catalyzes electron transport from NADPH to the inactive - oxidized form of thioredoxin $\left(\operatorname{Trx}-\mathrm{S}_{2}\right)$ and transforms it to an active, reduced form (Trx- $\left.(\mathrm{SH})_{2}\right)$ (Holmgren 1985). Reduced Trx can transfer reducing equivalents to many substrates such as insulin, coagulation factors, ribonuclease, choriongonadotropins and glucocorticoid receptor. Inside the cells Trx system acts also as a redox regulator, protects cells from damage caused by oxidative stress, scavenges ROS and controls a cellular redox balance. Trx system plays an important role in many physiological processes and it is also a prominent cell antioxidant (Koháryová et al. 2008). For many organisms its presence is essential to life.

In higher organisms, the components of the Trx system are located in: nucleus, cytoplasm, chloroplasts, mitochon-

Correspondence to: Marta Kollárová, Faculty of Natural Sciences, Comenius University, Department of Biochemistry, Mlynská dolina, 842 15, Bratislava, Slovak Republic

E-mail: kollarm@fns.uniba.sk dria, or they appears as extracellular or membrane-bound (Arnér and Holmgren 2000; Sőderberg et al. 2000; Watson and Jones 2003). Bacterial Trx system is located in the cytoplasm.

Thioredoxins (Trxs) are small thermostable proteins. Their common characteristic is a similar 3D structure, which consists of a core of five $\beta$-sheets surrounded by four $\alpha$-helixes with a typical conserved active site sequence Cys-X-X-Cys, (two cysteines separated by two other amino acids). This small globular protein has $90 \%$ of its residues involved in secondary structure elements. It is an excellent model for computer modelling and theoretical analysis for investigating the relationship between the structure of proteins and their functional properties (Štefanková et al. 2005). All previously studied Trxs have 27 to $69 \%$ sequence identity with E. coli thioredoxin (Arnér and Holmgren 2000). Despite of their conserved structures, Trxs differ in reactivity, which can be caused only by slight variations in the main "fold“.

The physiological functions of Trx in different organisms are diverse: from mainstream reactions where Trx acts as an electron carrier until to a large number of different highly specialized functions and reactions. Trx has a conserved role in the synthesis of DNA as a high-capacity hydrogen donor system for reducing the enzyme ribonucleotide reductase (Laurent et al. 1964), the Met-SO and PAPS reductase (Tsang 
and Schiff 1976; Ejiri et al. 1979). Thiol-redox control of Trx system also regulates chloroplast photosynthetic enzymes (Buchanan et al. 1994). However, Trx can modulate the activity of proteins through protein-protein binding to signal molecules, such as apoptosis signal-regulating kinase 1 (ASK1). Trx binds to the N-terminus and inhibits ASK1-kinase activity and thus also the ASK1-dependent apoptosis (Saitoh et al. 1998). Trx1-binding domain of ASK1 is a monomeric and rigid domain that forms a stable complex with reduced TRX1 with 1:1 molar stoichiometry (Kosek et al. 2014). By this mechanism E. coli Trx can increase processivity of T7 DNA polymerase and thereby affect the replication of phage T7 DNA (Huber et al. 1987).

In addition, Trx is able to interact with transcription factors and to undergo the posttranslational modifications such as: oxidation of the thiol groups of Cys-32 and -35, glutathionylation at Cys-73 (Casagrande et al. 2002), Snitrosylation at Cys-69 or Cys-73 (Haendeler et al. 2002), nitrative modification at Tyr-49 (Tao et al. 2006) and also glycation (Yuan et al. 2010). This capability is also consistent with the role of Trx system in angiogenesis signaling. Trx1 in endothelial cells exerts proangiogenic effects throughout a broad range of cellular activities operating to angiogenic function including: transcription, posttranslational modification, migration, proliferation, vascular network formation, apoptosis and intracellular signaling (Dunn et al. 2010).

Highly specialized function exhibit chloroplast Trxs, which act as messengers of redox signals from ferredoxin to target enzymes. Moreover, in vivo experiment by Luo et al. demonstrated that one class of chloroplast Trx, named asTrx-M can compensate a lack of different class of chloroplast Trx, named as Trx-F. Both Trxs act as of important redox regulators of $\mathrm{Mg}$-chelatase (Luo et al. 2012).

In recent years, the research is focused on the role of Trx against oxidative stress and its function in the control of programmed cell death and apoptosis (Arnér and Holmgren 2000). These functions depend on: the disulfide reductase activity of Trx, the amount of NADPH and from activity of TrxR.

Thioredoxin reductases (TrxRs) are dimeric enzymes belonging to the flavin-pyridine-nucleotide-disulfid oxidoreductase family that includes enzymes as lipoamide dehydrogenase and glutathione reductase (Williams 1992). TrxRs catalyze the transfer of two electrons from NADPH via FAD and N-terminal disulfide active site to the substrate. Bacterial TrxRs differ from human in many aspects. They have different: size, 3D structures, mechanism of catalysis and also position of active site (Luthman and Holmgren 1982). Unlike bacteria, mammalian $\operatorname{TrxR}(\mathrm{m} \operatorname{TrxR})$ is very similar to glutathione reductase by the structure and function. In addition, mTrxR contains a C-terminal extended arm (about 16 amino acids in length) which includes another redox-active motif. This motif in mammals include selenium-containing amino acid selenocysteine (Sec) - an analogue of cysteine in which the sulfur is replaced by selenium (Gladyshev et al. 1996; Tamura and Stadtman 1996). It is assumed, that thanks to highly-reactive active site of mTrxRs, they display also functions not linked with function of Trx (Arnér and Holmgren 2000).

Mammalian cells also contain three isoforms of TrxR: cytosolic protein TrxR1, the mitochondrial protein TrxR2 and the testis specific thioredoxin glutathione reductase (TGR) (Sun 2005).

TrxR reduces not only oxidized Trx, but has a wide range of other substrates such as: non-disulfide substrate selenide, lipid hydroperoxides and $\mathrm{H}_{2} \mathrm{O}_{2}$ (Arnér and Holmgren 2000). The direct protein substrate of human TrxR is for example glutaredoxin 2, which can be also reduced by a glutathione (Johansson et al. 2004). Other substrates of TrxR are: cytosolic peptide granulysin (Björkhem-Bergman et al. 2004) and cytotoxic and antibacterial NK-lysine (Andersson et al. 1996). There are also various non-protein substrates for mTrxR, for example, regeneration of active vitamin C, when TrxR reduce dehydroascorbate to ascorbate (May et al. 1997), and also reduction of ubiquinone (Xia et al. 2003; Nalvarte et al. 2004) and cytochrome c (Nalvarte et al. 2004).

Recently it has been discovered that thioredoxin and glutathione systems of mammals have an ability to provide electrons reciprocally and serve as a backup system for each other. In contrast, bacteria TrxRs are low molecular weight enzymes with structure and reaction mechanism distinct from mammalian TrxR. Many bacterial species possess specific thiol-dependent antioxiadant systems, and the significance of the $\operatorname{Trx}$ system in the defense against oxidative stress is different. Bacterial, low molecular weight TrxR is also very specific and except for Trx, it accepts only a small amount of other substrates. Particularly, the absence of a GSH-Grx system in some pathogenic bacteria such as Helicobacter pylori, Mycobacterium tuberculosis and Staphylococcus aureus makes the bacterial system essential for survival under oxidative stress. This provides an opportunity to kill these bacteria by targeting the TrxR-Trx system (Lu and Holmgren 2014). In addition, differences between mammalian and bacterial TrxRs open up a new potential for designing new drugs or antibiotics.

\section{Expression of thioredoxin system during oxidative stress in microbes}

Despite the high structural similarity of proteins of Trx system, they are unique in their characteristics and function. Trx is an antioxidant protein, whose expression is enhanced by various forms of oxidative stresses. It is also known, that exercise-induced oxidative stress may affect Trx induction (Sumida et al. 2004). During oxidative stress, expression 
of genes encoding proteins of Trx system is increasing and activities and location of proteins of Trx system proteins is changing considerably.

It was revealed, that expression of $\operatorname{Tr} x$ induced by oxidative stress is accompanied by the binding of transcription factor Nrf2 (NF-E2-related factor 2) to the specific ARE element (antioxidant responsive element) present in the promotor region of $\operatorname{Tr} x$ (Kim et al. 2001). Nrf2 is a redoxsensitive, leucine zipper transcription factor that was originally identified as a binding protein of the locus control region of $\beta$-globin gene (Moi et al. 1994). ARE is a cis-acting regulatory element or enhancer sequence, which was found in the promoter regions of genes encoding enzymes and proteins belonging to the phase II detoxification, which includes the proteins of Trx system (Lee and Johnson 2004).

In E. coli were identified two regulons directly responsive to $\mathrm{H}_{2} \mathrm{O}_{2}$-induced oxidative stress: transcriptional regulator OxyR, which binds to a target place and activates gene expression by contact with alpha subunit of DNA polymerase and regulon SoxRS. SoxR and SoxS serve as response regulators to the superoxide of enterobacteria (Christman et al. 1989; Tao et al. 1993; Nunoshiba 1996).

Although many gram-positive bacteria contain homologues of OxyR to control the expression of Trx genes, they use also other regulons such as sigma $(\sigma)$ factors. $\sigma$ factor is the specificity factor, which is additional subunit of RNA polymerase that directs RNA polymerase to the promoters of selective gene sets. Essential trxA gene in B. subtilis is controlled by $\sigma^{A}$ factor and initiation of transcription is induced by $\mathrm{H}_{2} \mathrm{O}_{2}$. During continual stress, $\sigma^{\mathrm{B}}$ factor is also transcribed (Scharf et al. 1998).

In $S$. coelicolor, $65 \sigma$ factors of which 45 are ECF (extracytoplasmic function) $\sigma$ factors, were identified. Previously described ECF $\sigma$ factors in S. coelicolor respond to external stimuli and activate genes involved in disulphide stress, cellwall homeostasis and aerial mycelium development (Paget et al. 2001). $\sigma^{\mathrm{R}}$ factor $(25 \mathrm{kDa})$, encoded by sigR gene, has been identificated in $S$. coelicolor like a part of a system that senses and responds to thiol oxidation through the regulation of the transcription of many genes involved in the maintenance of thiol-disulphide redox homeostasis. The trxBA operon, encoding TrxR and Trx in S. coelicolor, was found to be under the direct control of $\sigma^{\mathrm{R}}$. $\operatorname{tr} \times B A$ is transcribed from two promoters, $\operatorname{tr} x B p 1$ and $\operatorname{tr} x B p 2$, separated by 5-6 bp. Paget et al. discovered, that exposure of $S$. coelicolor hyphae to oxidative stress causes intracellular thiol oxidation, which induces $\sigma^{\mathrm{R}}$ activity, leading to increased production of Trx and TrxR, as well as $\sigma^{\mathrm{R}}$ itself (Paget et al. 1998). $\sigma^{\mathrm{R}}$ factor binds to RsrAbinding domain under normal reducing conditions. RsrA $(12 \mathrm{kDa})$ is a cognate anti-sigma factor, it is redox-sensitive zinc metalloprotein, which modulates $\sigma^{\mathrm{R}}$ activity. Exposure to disulphide stress induces the formation of one or more intramolecular disulphide bonds in RsrA, which causes it to lose afinity for $\sigma^{\mathrm{R}}$, releasing $\sigma^{\mathrm{R}}$ to activate $\operatorname{tr} x B A$ transcription $\left(\sigma^{\mathrm{R}}\right.$-dependent transcription). Increased tr $x B A$ expression, in turn, leads to the back thioredoxin-dependent reduction of oxidized RsrA back to its $\sigma^{\mathrm{R}}$-dependent transcription (Kang et al. 1999). In addition, $\sigma^{\mathrm{R}}$ positively autoregulates the expression of the sigR-rsrA operon (Paget et al. 1998). Upon re-estabilishment of normal reduced thiol levels by the thioredoxin system, $\sigma^{\mathrm{R}}$ activity is switched off.

In all studied bacterial organisms, Trx and $\operatorname{TrxR}$ are expressed as two proteins except for Mycobacterium leprae, where Trx is expressed with TrxR from one gene. Result of expression is a hybrid protein with subunits linked by hydrophilic peptide linker (Wieles et al. 1995).

\section{Expression of thioredoxin system proteins during oxi- dative stress in mammals}

In pathophysiological conditions induced by oxidative stress was observed specific intracellular localization of Trx and TrxR. Although Trx1 have not localization sequence, it has been shown that a certain concentration of $\operatorname{Trx} 1$ is also present in the cell nucleus in normal physiological conditions and significantly increased after stimulation with oxidizing agents (Watson and Jones 2003). The translocation of Trx from the cytoplasm to the nucleus was first observed in cultures of keratinocytes after UV irradiation (Masutani et al. 1996). Translocation can be also caused by other reagents and conditions such as: hypoxia, exposure to $\mathrm{H}_{2} \mathrm{O}_{2}$, hemin, treatment of cells with PMA (phorbol 12-myristate 13-acetate) (Hirota et al. 1997; Ema et al. 1999). It is assumed that, the transfer of Trx is done by another protein with a nuclear import sequence, and this process can be influenced by caloric restriction (Cho et al. 2003). The presence of Trx1 has been also demonstrated in the extracellular space, into which reaches by unknown mechanism (Tanudji et al. 2003).

Trx in blood plasma even serves as a biomarker of oxidative stress (Nakamura et al. 1998; Nishinaka et al. 2001). Elevated plasma Trx was found in the development of a number of diseases, including hepatocellular carcinoma (Rubartelli et al. 1995), AIDS (Nakamura et al. 1996), Sjögren's syndrome (Saito et al. 1996) and rheumatoid arthritis (Yoshida et al. 1999).

High levels of antioxidant proteins, including increased expression of Trx were observed in cancer cells, which are often under high oxidative or hypoxic stress. Increased expression of Trx has been demonstrated in cells of many primary cancers including: cervical cancer (Cha et al. 2009), cancer of colorectal tract (Raffel et al. 2003), lung cancer (Kim et al. 2003), pancreas cancer (Han et al. 2002) and stomach cancer (Toddy et al. 2000). On the other hand, many studies suggest that overproduction of Trx plays not only active-protective role. Overproduction may promote 
cancer proliferation in a number of ways such as: 1.) by direct stimulation of cancer progress, 2.) by inhibition of apoptosis in cancer cells, 3 .) by stimulating the invasive and metastatic activity, but also 4.) by the creation of chemotherapy resistance in cancer cells induced by overproduction of Trx, which has been demonstrated for example in patients receiving cisplatin (Yokomizo et al. 1995; Sasada et al. 1996; Karlenius and Tonissen 2010). In early stage cancer patients, who are commonly treated by radiotherapy, Trx system was identified as a potential modulator of radiosensitivity (Smart et al. 2004; Mehta et al. 2009).

\section{Thioredoxin system of selected pathogens as a therapeutic target}

The cytoplasm of pathogens, like as in all organisms, is a highly reduced environment, in which cysteines of proteins are maintained in reduced state. But pathogens are also exposed to oxidative stress, which is produced by the metabolic pathways of aerobic pathogens themselves (reactive oxygen species) or it is produced by host organism as a defense against pathogens (reactive oxygen and nitrogen metabolites). During the increasing oxidative stress, pathogens activate different redox mechanisms to detoxify reactive oxygen metabolites, to reduce unwanted disulfide bonds and to repair damage in their cell.

In most cases, the organisms contain multiple $\operatorname{Tr} x$ proteins. Their individual functions are still studying and revealing. Study is very difficult, because it indicates a complex network of antioxidant processes. Similarly as in many non-pathogenic organisms' genomes, also in pathogens have been identified a number of Trx and TrxR. For example, Trx system is a major thiol-disulfide redox system in gram-negative, opportunistic pathogen $B$. fragilis (Rocha et al. 2007) and contains six genes encoding homologues of Trx and one gene for TrxR (Reott et al. 2009). Recently studies revealed that not all Trx proteins are still active and providing an active protection. It is supposed that they can be a part of "redundant system", which ensures survival under special condition. It was found that one of three revealed thioredoxins in $M$. tuberculosis, TrxA has weak capacity to act as a disulfide reductase and it is not a substrate for TrxR under tested assay condition (Akif et al. 2008).

Pathogens lacking cooperating glutaredoxin-glutathione system have the Trx system as main redox system. Such organism is H. pylori, whose Trx system is composed of two Trx (Baker et al. 2001) and one TrxR (Gustafsson et al. 2007). Important physiological function was confirmed by the mutation experiments, in which mutations of Trx caused increased sensitivity $H$. pylori against to oxidative and nitrogen stress (Comtois et al. 2003).
Another example is the opportunistic pathogen Bacteroides fragilis, which belongs to the most tolerant obligate anaerobes to atmospheric oxygen and is able to survive a long time in a fully aerobic environment (Tally et al. 1975). This feature is allowed by large number of genes, which are expressed in aerobic conditions, including the genes for the Trx (Sund et al. 2008). Entamoeba histolytica affecting amoebic dysentery or amoebic liver abscess in humans and primates also belongs to the anaerobic parasites, which lack the glutathione system and an unusual form of glutathionetrypanothione (Ariyanayagam and Fairlamb 1999; Ryan and Ray 2004). For virulence factor of this organism is considered its ability to deal with the increased oxidative stress and with high concentration of reactive oxygen metabolites (Akbar et al. 2004). The main redox system is Trx system with peroxiredoxin and cofactor NADPH, which can successfully reduce hydroperoxides (Arias et al. 2007).

A role of Trx system against oxidative stress is also important for mycobacteria that resides in the host organism in macrophages, what presents form of virulence. Macrophages, neutrophils, and other fagocyting cells are key antimicrobial components of the immune response, due to the fact that they can generate a large amount of highly toxic molecules as reactive oxygen and nitrogen metabolites, and hydrolytic enzymes such as acid hydroxylase (Chan et al. 1992; Clemens and Horwitz 1995; Rich et al. 1997). Despite this toxic environment $M$. tuberculosis can survive thanks to several mechanisms (Pieters, 2008). Mycobacteria and other actinomycetes (e.g. S. coelicolor) do not synthesize glutathione but in cells they have mycothiol (Newton et al. 1996) and their redox regulation is also under control of Trx system. In mycobacteria, it has been confirmed that mycothiol plays important role in detoxification, quenching reactive oxygen and nitrogen metabolites formed in phagocytes during infection and provides reducing equivalents for peroxiredoxins (Shinnick et al. 1995; Zhang et al. 1999; Jaeger et al. 2004). In this way, Trx system is essential for pathogens and helps them survive in host cells. In 2008, TrxR M. tuberculosis was selected from nearly 4000 gene products, together with 541 other proteins as promising therapeutic target for the development of new antituberculotics based on bioinformatic predictions (Raman et al. 2008).

Thank to the clear differences in the properties of TrxR from bacteria and higher organisms (such as size, substrate specificity, structure and mechanism of catalysis) TrxR had just become a new promising therapeutic target for the preparation of new antibiotics (Gromer et al. 1998a; Becker et al. 2000; Hirt et al. 2000). In many cases, TrxR is essential enzyme for the physiology of the organism and deletion or inactivation of $\operatorname{Tr} x R$ encoding gene may cause lethality, such as in the most causative agent of staph infections - gram-positive bacterium Staphylococcus aureus (Uziel et al. 2004). 
TrxR from $P$. falciparum was identified as a promising target for the development of new antimalarial drugs (Banerjee et al. 2009). Using high-throughput screening program, specific inhibitors were identified allowing study of TrxR in relation to survival of the parasites (Williams et al. 2000).

The current trend in novel drug development is rational design of inhibitors, based on 3D structures of therapeutical targets. For this purpose, it has been crystallized and solved 3D structures of TrxR from gastric pathogen H. pylori (Gustafsson et al. 2007) and M. tuberculosis (Akif et al. 2005).

\section{Importance of thioredoxin system in medicine}

Thanks to explosive growth of studies focused on oxidative stress and oxidative damage, it has been found that a number of completely different diseases (such as infarct, stroke, lung cancer, cataracts, diabetes, and others) have a similar reason (Young et al. 2004; Schweizer et al. 2004; Varsik et al. 2006). The key role in their genesis plays a free radicals and oxidative stress, which affect formation of undesirable disulfides. After recording of oxidative stress, changes in the concentration and activity of proteins of Trx system are displayed. Especially, in comparison with normal tissues, many primary tumors overproduce proteins of Trx system, which helps to increase the proliferation of malignant cells (Powis et al. 2000).

The cytoplasm and mitochondria contain equivalent $\operatorname{Tr} x$ systems and inhibition of either system can lead to activation of apoptotic signaling pathways. There are a number of inhibitors with chemotherapy applications that target either Trx or TrxR to induce appoptosis in cancer cells. Suberoylanilide hydroxamic acid (SAHA) is effective against many cancer cells and functions by up-regulating an endogenous inhibitor of Trx. Other compounds target the selenocysteine-containing active site of TrxR. These include gold compounds, platinum compounds, arsenic trioxide, motexafin gadolinium, nitrous compounds and various flavonoids. Inhibition of TrxR leads to an accumulation of oxidized Trx resulting in cellular conditions that promote apoptosis. In addition, some compounds also convert TrxR to a ROS generating enzyme (Tonissen and Di Trapani 2009).

Mammalian TrxR isoforms in the cytosol and the mitochondria are essential selenoenzymes with a selenocysteine in the active site. These enzymes display remarkably broad substrate specificity but are also targets for existing chemotherapeutic drugs. Mammalian TrxR enzymes are linked to selenium metabolism as a result of being selenoproteins, but can also directly reduce low molecular selenium compounds like selenite and have been implicated in the che- moprevention effects of selenium against cancer. Numerous scientific reports describe higher expression of Trx and TrxR in some, but not all tumours. Some data suggest that high Trx could be linked to resistance to chemotherapies while others suggest that high $\operatorname{Trx}$ and $\operatorname{TrxR}$ may induce apoptosis and reduce the mitotic index of certain tumors linked to the p53 dependent cell death. Recent data suggest that TrxR is essential for the carcinogenic process and invasive phenotype of cancer. Both Trx and TrxR have been regarded as interesting targets for chemotherapy (Arnér and Holmgren 2006).

The difficulty of delivering clinically relevant doses to kill all tumour cells in patients with lung cancer remains a true clinical problem. This is partly due to the organs at risk, i.e. normal lung and spinal cord that limit the total dose of irradiation that can be delivered to the tumour. The thioredoxin system is promising target when aiming to overcome the problem of clinical radiation resistance. Altered cellular redox status and redox sensitive thiols contributing to induction of resistance strongly connect the ubiquitous redox enzyme TrxR to the cellular response to ionizing radiation.

The study reveals increased radiation sensitivity of cultured lung cancer cells [cell line U1810] with inhibition of the multi-functional redox enzyme TrxR by the phosphine gold(I) complex $[\mathrm{Au}(\mathrm{SCN})(\mathrm{PEt} 3)]$ demonstrated by a decreased ability to recover after radiation treatment. The data clearly demonstrate an important role of TrxR in radiation resistance, and warrant further studies to elucidate the specific mechanisms of TrxR involvement in resistance development. Pharmacological inhibition of TrxR is an attractive treatment strategy to optimize the efficacy of radiation therapy and TrxR inhibition (Selenius et al. 2012).

\section{Inhibitors of Trx}

By several biological screenings were already detected different, small organic compounds which inhibit the Trx system.

Effective inhibitors of Trx-1/TrxR in MCF-7 human breast cancer with an $\mathrm{IC}_{50} 31-37 \mu \mathrm{M}$ are alkyl 2-imidazolyl disulfides (Powis et al. 1998). Growth inhibition of two breast tumor cell lines was founded by Palmarumycin $\mathrm{CP}_{1}$ with manifested $\mathrm{IC}_{50} 1 \mu \mathrm{M}$ and $2.4 \mu \mathrm{M}$. This inhibitor is a natural fungal metabolite belonging to the family of napthoquinone spiroketal compounds with a direct effect on Trx (Wipf et al. 2001).

Inhibitor PX-12 (1-methylhydroxypropyl 2-imidazolyl disulfide) causes inhibition of Trx-dependent cell growth (Wipf et al. 2001) by irreversible thiolalkylation of Cys73 in Trx-1 and its antitumor activity was demonstrated against human tumor xenografts in scid mice (Kirkpatrick et al. 
1998). The median $\mathrm{IC}_{50}$ for inhibition of several tumor celllines is $8.1 \mu \mathrm{M}$ (Powis and Montfort 2001).

Para-quinone NSC401005, natural product of pleurotin was discovered by COMPARE analysis. $\mathrm{IC}_{50}$ of this compound against Trx-1/TrxR was determined as $0.17 \mu \mathrm{M}$, but using this inhibitor for testing on other types of tumor cells, the average $\mathrm{IC}_{50}$ was only $21.5 \mu \mathrm{M}$ (Kunkel et al. 1997; Patent application US $20020049221 \mathrm{~A} 1)$.

Compound pleutropin NSC-131233 together with PX12 reduced the activity of the transcription factor HIF-1a (which responds to hypoxia) and also the expression of downstream targets of HIF-1, VEGF and iNOS in vitro (Welsh et al. 2003).

AW464 (4-hydroxy-4-(bezothiazol-2-yl)cyclohexadienone) is effective against renal- and colon-cancer cell lines, where inhibits Trx redox cycling by forming an irreversible complex with the active-site thiol groups in the reduced Trx (Pallis et al. 2003). AW464 has anti-proliferative activity on tumor cell lines and endothelial cells in vitro, but not fibroblasts, with $\mathrm{IC}_{50}$ value of $0.5 \mu \mathrm{M}$ (Mukherjee et al. 2005).

MOL294 (methyl (4R/S)-4-hydroxy-4-[((5S,8S)/ (5R,8R))-8-methyl-1,2-dioxo-2-phenyl-2,3,5,8-tetrahydro$1 \mathrm{H}$-[1,2,4] triazolo[1,2-a]pyridazin-5-yl]2-butynoate) is a small organic molecule, which is designed to mimic the extended $(\beta)$ strand of peptide substrates that bind Trx. MOL 294 inhibits NF-kB-mediated expression of vascular cell adhesion molecule 1 with $\mathrm{IC}_{50}$ of $2.5 \mu \mathrm{M}$ in vitro (MisraPress et al. 2002).

\section{Inhibitors of TrxR}

Recent studies have elucidated that TrxR was upregulated in many malignant tumors and inhibition of TrxR could prevent the tumor initiation and progression, suggesting TrxR to be a promising target for cancer therapy and the highly nucleophilic and accessible selenocysteine (Sec) active site might be the prime target for drug design. Various kinds of TrxR inhibitors have been developed as anticancer agents for years. TrxR inhibitors are divided into three classes, including metal containing inhibitors, naturally occurring products and their derivates and other newly emerged inhibitors (Yang et al. 2012).

Mammalian TrxRs have wide substrate specificity, because in addition to N-terminal redox active disulfide site "-Cys-Val-Asn-Val-Gly-Cys-" contain also secondary redox centre in the C-terminal with a typical "-Gly-CysSec-Gly-COOH” sequence. This sequence is essential for catalysis and easily accessible for the different substrates and inhibitors (Fujiwara et al. 2001). Summary of $\mathrm{IC}_{50}$ of selected inhibitors are in Table 1.

\section{Auranofin (AF)}

Selenocysteine (Sec) group in the active site of reduced TrxR shows high reactivity towards metal ions (Witte et al. 2005). Organic gold compounds such as auranofin (2,3,4,6-tetra-Oacetyl-1-thio- $\beta$-D-glucopyranosato-S-(triethylphosphine) gold) exert cytotoxic effects by causing direct mitochondrial

Table 1. Overview of selected thioredoxin reductase (TrxR) inhibitors

\begin{tabular}{|c|c|c|c|c|}
\hline Inhibitor & Description & Source of TrxR & $\mathrm{IC}_{50}(\mu \mathrm{M})$ & References \\
\hline Myricetin & \multirow{3}{*}{ Flavonol } & \multirow{9}{*}{ rat } & 0.62 & \multirow{5}{*}{ Lu et al. 2006} \\
\hline Quercetin & & & 0.97 & \\
\hline Catechin & & & 6.6 & \\
\hline Pelargonidin & Anthocyanidin & & 4.2 & \\
\hline Taxifolin & Flavanone & & 6.2 & \\
\hline $\mathrm{HgCl}_{2}$ & \multirow{2}{*}{ Mercury compound } & & 0.0072 & Carvalho et al. 2008 \\
\hline Methylmercury (MeHg) & & & 0.0197 & Wagner et al. 2010 \\
\hline Motexafin gadolinium & $\begin{array}{l}\text { Gadolinium-containing } \\
\text { compound }\end{array}$ & & 6 & Hashemy et al. 2006 \\
\hline $\begin{array}{l}\text { Benzene-sulfonyl-6F-indole- } \\
\text { substitued quinol }\end{array}$ & Quinol analog & & 4.3 & Chew et al. 2008 \\
\hline Auranofin & \multirow{2}{*}{ Gold-containing molecule } & human placenta & 0.02 & Gromer et al. 1998b \\
\hline Auxil & & human cancer cells & 0.21 & Rigobello et al. 2004 \\
\hline \multirow{2}{*}{ Hypericin } & \multirow{4}{*}{ Naphthodianthrone } & cytosolic rat liver & 157.08 & \multirow{4}{*}{ Sorrentino et al. 2011} \\
\hline & & mitochondrial rat liver & 43.12 & \\
\hline \multirow{2}{*}{ Pseudohypericin } & & cytosolic rat liver & 4.4 & \\
\hline & & mitochondrial rat liver & 7.45 & \\
\hline
\end{tabular}


damage through selective modification of the selenol active site in TrxR (Rigobello et al. 2004) and induces mitochondrial permeability, which results in the release of cytochrome c from mitochondria into cytoplasm with consequent apoptotic cell death (Cox et al. 2008). AF-like gold complexes synthetized by Gandin et al. are super inhibitors of TrxR1 and $\operatorname{TrxR} 2$ with $\mathrm{IC}_{50}$ values with low to sub-nanomolar range and also inhibits cancer cell growth (Gandin et al. 2010). AF is probably the most effective inhibitor of mammalian TrxR found to date and might be utilized as an anticancer agent to induce apoptotic cell death.

To a first approximation, $\operatorname{TrxR}$ inhibition may be attributed to binding of $\mathrm{Au}$ to the $\mathrm{C}$-terminal redox-active -Gly-Cys-Sec-Gly sequence, as recently suggested by MALDI-TOF experiments. However, selenols and selenides have higher affinity for Au than thiols for several factors: 1 . the general afinity between heavy polarizable atoms, 2 . the consequent higher nucleophilic strenght of Se than S, 3. the lower pKa of selenols (5.2) than thiols (8.0), whereby the - SeH group of the Sec residue is completely dissociated at physiological $\mathrm{pH}$, which makes - Se- a better nucleophile than the undisociated thiol (Di Sarra et al. 2013).

\section{Arsenic trioxide (ATO)}

ATO has been used as an anticancer drug for several thousands of years in traditional medicine and recently has been shown as an effective cancer therapeutic drug for acute promyelocytic leukemia and has potential anticancer activity against a wide range of solid tumors. ATO exerts its efect mainly through elevated oxidative stress, but the exact molecular mechanism remains elusive. Lu et al. discovered that ATO irreversibly inhibits mammalian Trx with an $\mathrm{IC}_{50}$ of $0.25 \mu \mathrm{M}$. Both the N-terminal redox-active dithiol and the C-terminal selenothiol-active site of reduced TrxR may participate in the reaction with ATO. The inhibition of MCF-7 cell growth by ATO was correlated with irreversible inactivation of TrxR, which subsequently led to Trx oxidation. The inhibition of TrxR by ATO was attenuated by $\mathrm{GSH}$, and GSH depletion by buthionine sulfoximine enhanced ATO-induced cell death. These results strongly suggest that the ATO anticancer activity is by means of a Trx system-mediated apoptosis. Blocking cancer cell DNA replication and repair and induction of oxidative stress by the inhibition of both Trx and GSH systems are suggested as cancer chemotherapeutic strategies (Lu et al. 2007).

\section{Cis platin}

Thanks to strong nucleophilicity of Cys/Sec residue in TrxR it was supposed the reaction with potential electrophilic molecule - cisplatin (cis-diamminedichloroplatinum (II)). Sasada et al. showed that cisplatin inhibits isolated cellular
TrxR with celullar enzyme activity to $\sim 50 \%$ at a concetration of $10 \mu \mathrm{M}$ (Sasada et al. 1999).

Gold-based compounds are essentially ultilized for the treatment of rheumatoid arthritis and they have also been tested for other pathologies such as AIDS, bronchial asthma, malaria and together with platinum-containing complexes can be also used as cancer chemotherapeutic drugs (Mirabelli et al. 1986; Shaw 1999).

\section{Curcumin}

Another type of inhibitor - curcumin, is yellow lipid-soluble polyphenol from the plant Curcuma longa. Curcumin is a part of food additive turmeric, in which 3-4\% of weight is consisted from yellow pigments curcuminoids. It is a mixture of curcumin $(94 \%)$, demethoxy curcumin $(6 \%)$ and bis- demethoxy curcumin $(0.3 \%)$. It has been shown that curcumin is a potent inhibitor of tumor initiation in vivo and also in vitro (Aggawarl et al. 2003). Later, it was found that curcumin is an antioxidant with anticancer activity and can irreversibly inhibit TrxR by simultaneously elicited an NADPH oxidase activity of the enzyme (Fang et al. 2005). Following these discovery, explosive number of synthetic analogs of curcumin with $\mathrm{IC}_{50}$ values from the nano- to the low micro- molar range was prepared and tested (Liu et al. 2008; Zhong et al. 2008). Very interesting are the recent studies which shown, that curcumin can turn to be a prooxidant to produce ROS and induce oxidative stress in cells (Han et al. 2011; Kuo et al. 2011). Cai et al. revealed, that curcumin modified TrxR1 oxidizes NADPH to generate superoxides in vitro, and curcumin-treated HeLa cells have elevated intracellular ROS production and curcumin can also drastically down-regulate Trx1 level as well as its enzyme activity in HeLa cells (Cai et al. 2012).

\section{Flavonoids}

Another promising group of TrxR inhibitors are flavonoids - products of secondary metabolism with widespread biological properties such as: antioxidant, antiproliferative, antiinflammatory or antibiotic activity, which can contribute to their chemoprevention for the development of cancer and cardiovascular disease (Yang et al. 2001; Ross and Kasum 2002). In some cases, they exhibit pro-oxidant properties (Williams et al. 2004). Lu et al. tested flavonoides from all six categorized group to inhibition of mammalian TrxR and found out, that 3-hydroxyl-containing flavonoids such as quercetin, myricetin, taxifolin, catechin and pelargonidin exhibited an NADPH-, concentration- and time-dependent inhibitory effect (Lu et al. 2006).

It was investigated the inhibition of mammalian TrxR by flavonoids which have been presumed to be cancer chemoprevention agents because of their antioxidant activities. 
Myricetin and quercetin were found to have strong inhibitory effects on mammalian TrxRs with $\mathrm{IC}_{50}$ values of 0.62 and $0.97 \mu \mathrm{M}$, respectively. The inhibition was shown to be concentration-, NADPH- and time-dependent and involved an attack on the reduced COOH-terminal of -Cys-Sec-Gly active site of $\operatorname{TrxR}$. Oxygen-derived superoxide anions enhanced the inhibitory effect whereas anaerobic conditions attenuated inhibition. Spectral analysis suggested that the flavonoids might perform their inhibitory effects via semiquinone radicals. Additionaly, the flavonols had the potential to inhibit the growth of A549 cells with the same potency as inhibition of TrxR. TrxR activity in the cell lysates was reduced on treatment with myricetin $>50 \mu \mathrm{M}$, which coincided with the oxidation of Trx. The cell cycle was arrested in $S$ phase by quercetin and accumulation of cells in sub-G1 was observed in response to myricetin. Thus, the anticancer activity of quercetin and myricetin may be due to inhibition of TrxR, consequently inducing cell death ( $\mathrm{Lu}$ et al. 2006).

Bacterial TrxR do not have secondary active site with highly reactive Sec group and this is probably one of the reasons why many mammalian TrxR inhibitors are without effect. Example is benzenesulfonyl-6F-indole-substitued quinol that selectively inhibits mammalian $\operatorname{TrxR}$ but is without effect on bacterial TrxR and glutathione reductase (Chew et al. 2008).

\section{Ebselen}

Selenoorganic compound ebselene [2-phenyl-1,2-benzisoselenazol-3(2H)-one] affects bacterial and mammalian TrxR via different mechanisms. Ebselene is an antioxidant and anti-inflammatory selenoorganic compound used in clinical trials against e.g. stroke (Wójtowicz et al. 2004). Mechanism of its action is mainly through its interactions with the mammalian TrxR and Trx providing the electrons for reduction of hydrogen peroxide. Holmgren et al. discovered that ebselene is not a substrate of $E$. coli TrxR but instead it is a competitive inhibitor for the reduction of $\operatorname{Trx}$ with $\mathrm{K}_{\mathrm{i}}$ of $0.15 \mu \mathrm{M}$. Also $E$. coli mutants lacking glutahione reductase and glutathione are much more sensitive to inhibition by ebselene (Holmgren et al. 2011).

\section{Conclusion}

Proteins of thioredoxin system play essential regulatory role in all living organisms thanks to their huge functional diversity. The number of studies that reveal new physiological as well as pathological mechanisms in which these proteins play irreplaceable role is still increasing.

$\operatorname{Trx}$ and TrxR are interesting targets for therapeutic usage, and at present there is a rapid development of potential inhibitors, which are used not only in cancer therapy, but also in the development of new drugs against pathogens.

One of the best ways to create or design the effective inhibitor is using of compounds, which are designed after determination of protein structure of revealed mechanism of action.

Acknowledgements. This publication is the result of the project implementation: Development of Competence center for research and development in molecular medicine, ITMS: 26240220071 supported by the Research \& Development Operational Programme funded by the ERDF. This publication is also the result of the project implementation: Comenius University in Bratislava Science Park supported by the Research and Development Operational Programme funded by the ERDF, Grant number: ITMS 26240220086. This publication is also the result of the project implementation (ITMS 26240120027) supported by the OPRaD funded by the ERDF. This contribution is the result of the project implementation (ITMS 26240120003).

\section{References}

Aggarwal B. B., Kumar A., Bharti A. C. (2003): Anticancer potential of curcumin: preclinical and clinical studies. Anticancer Res. 23, 363-398

Akbar M. A., Chatterjee N. S., Sen P., Debnath A., Pal A., Bera T., Das P. (2004): Genes induced by a high-oxygen environment in Entamoeba histolytica. Mol. Biochem. Parasitol. 133, $187-196$ http://dx.doi.org/10.1016/j.molbiopara.2003.10.006

Andersson M. (1996): NK-lysin, a disulfide-containing effector peptide of T-lymphocytes, is reduced and inactivated by human thioredoxin reductase: implication for a protective mechanism against NK-lysin cytotoxicity. J. Biol. Chem. 271, 10116-10120 http://dx.doi.org/10.1074/jbc.271.17.10116

Arias D. G., Gutierrez C. E., Iglesias A. A., Guerrero S. A. (2007): Thioredoxin-linked metabolism in Entamoeba histolytica. Free Radic. Biol. Med. 42, 1496-1505 http://dx.doi.org/10.1016/j.freeradbiomed.2007.02.012

Ariyanayagam M. R., Fairlamb A. H. (1999): Entamoeba histolytica lacks trypanothione metabolism. Mol. Biochem. Parasitol. 103, 61-69 http://dx.doi.org/10.1016/S0166-6851(99)00118-8

Arnér E. S., Holmgren A. (2000): Physiological functions of thioredoxin and thioredoxin reductase. Eur. J. Biochem. 267, 6102-6109 http://dx.doi.org/10.1046/j.1432-1327.2000.01701.x

Arnér E. S., Holmgren A. (2006): The thioredoxin system in cancer. Semin Cancer Biol. 16, 420-426 http://dx.doi.org/10.1016/j.semcancer.2006.10.009

Baker L. M., Raudonikiene A., Hoffman P. S., Poole L. B. (2001): Essential thioredoxindependent peroxiredoxin system from Helicobacter pylori: genetic and kinetic characterization. J. Bacteriol. 183, 1961-1973 http://dx.doi.org/10.1128/JB.183.6.1961-1973.2001 
Banerjee A. K., Arora N., Murty U. S. N. (2009): Structural model of the Plasmodium falciparum Thioredoxin reductase: a novel target for antimalarial drugs. J. Vector Borne Dis. 46, 171-183

Becker K., Gromer S., Schirmer R. H., Muller S. (2000): Thioredoxin reductase as a pathophysiological factor and drug target. Eur. J. Biochem. 267, 6118-6125 http://dx.doi.org/10.1046/j.1432-1327.2000.01703.x

Björkhem-Bergman L., Jönsson-Videsäter K., Paul Ch., Björnstedt M., Andersson M. (2004): Mammalian thioredoxinreductase alters cytolytic activity of an antibacterial peptide. Peptides 25, 1849-1855 http://dx.doi.org/10.1016/j.peptides.2004.06.012

Buchanan B. B., Schurmann P., Decottignies P., Lozano R. M. (1994): Thioredoxin: a multifunctional regulatory protein with a bright future in technology and medicine. Arch. Biochem. Biophys. 314, 257-260 http://dx.doi.org/10.1006/abbi.1994.1439

Casagrande S., Bonetto V., Fratelli M., Gianazza E., Eberini I., Massignan T., Salmona M., Chang G., Holmgren A., Ghezzi P. (2002): Glutathionylation of human thioredoxin: a possible crosstalk between the glutathione and thioredoxin systems. Proc. Natl. Acad. Sci. USA 99, 9745-9749 http://dx.doi.org/10.1073/pnas.152168599

Carvalho C. M. L., Chew E. H., Hashemy S. I., Lu J., Holmgren A. (2008): Inhibition of the human thioredoxin system-a molecular mechanism of mercury toxicity. J. Biol. Chem. 283, $11913-11923$ http://dx.doi.org/10.1074/jbc.M710133200

Cha M. K., Suh K. H., Kim I. H. (2009): Overexpression of peroxiredoxin I and thioredoxin1 in human breast carcinoma. J. Exp. Clin. Cancer. Res. 28, 93

http://dx.doi.org/10.1186/1756-9966-28-93

Chan J., Xing Y., Magliozzo R. S., Bloom B. R. (1992): Killing of virulent Mycobacterium tuberculosis by reactive nitrogen intermediates produced by activated murine macrophages. J. Exp. Med. 175, 1111-1122 http://dx.doi.org/10.1084/jem.175.4.1111

Chew E. H., Lu J., Bradshaw T. D., Holmgren A. (2008): Thioredoxin reductase inhibition by antitumor quinols: a quinol pharmacophore effect correlating to antiproliferative activity. FASEB J. 22, 2072-2083 http://dx.doi.org/10.1096/fj.07-101477

Cho C. G., Kim H. J., Chung S. W., Jung K. J., Shim K. H., Yu. B. P., Yodoi J., Chung H. Y. (2003): Modulation of glutathione and thioredoxin systems by calorie restriction during the aging process. Exp. Gerontol. 38, 539-548 http://dx.doi.org/10.1016/S0531-5565(03)00005-6

Christman M. F., Storz G., Ames B. N. (1989): OxyR, a positive regulator of hydrogen peroxide-inducible genes in Escherichia coli and Salmonella typhimurium, is homologous to afamily of bacterial regulatory proteins. Proc. Nat. Acad. Sci. USA 86, 3484-3488 http://dx.doi.org/10.1073/pnas.86.10.3484

Comtois S. L., Gidley M. D., Kelly D. J. (2003): Role of the thioredoxin system and the thiol-peroxidases Tpx and Bcp in mediating resistance to oxidative and nitrosative stress in Helicobacter pylori. Microbiology 149, 121-129 http://dx.doi.org/10.1099/mic.0.25896-0
Cox A. G., Brown K. K., Arner E. S., Hampton M. B. (2008): The thioredoxin reductase inhibitor auranofin triggers apoptosis through a Bax/Bak-dependent process that involves peroxiredoxin 3 oxidation. Biochem. Pharmacol. 76, 1097-1109 http://dx.doi.org/10.1016/j.bcp.2008.08.021

Di Sarra F., Fresch B., Bini R, Saielli G., Bagno A. (2013): Reactivity of auranofin with selenols and thiols implications for the anticancer activity of gold(i) compounds. Eur. J. Inorg. Chem. $15,2718-2727$ http://dx.doi.org/10.1002/ejic.201300058

Ejiri S. I., Weissbach H., Brot N. (1979): Reduction of methionine sulfoxide to methionine by Escherichia coli. J. Bacteriol. 139, 161-164

Ema M., Hirota K., Mimura J., Abe H., Yodoi J., Sogawa K., Poellinger L., Fujii-Kuriyama Y. (1999): Molecular mechanisms of transcription activation by HLF and HIFlalpha in response to hypoxia: their stabilization and redox signal-induced interaction with CBP/p300. EMBO J. 18, 1905-1914 http://dx.doi.org/10.1093/emboj/18.7.1905

Fang J. G., Lu J., Holmgren A. (2005): Thioredoxin reductase is irreversibly modified by curcumin - a novel molecular mechanism for its anticancer activity. J. Biol. Chem. 280, 25284-25290 http://dx.doi.org/10.1074/jbc.M414645200

Fujiwara N., Fujii T., Fujii J., Taniguchi N. (2001): Roles of N-terminal active cysteines and C-terminal cysteine-selenocysteine in the catalytic mechanism of mammalian thioredoxin reductase. J. Biochem. 129, 803-812 http://dx.doi.org/10.1093/oxfordjournals.jbchem.a002923

Gandin V., Fernandes A. P., Rigobello M. P., Dani B., Sorrentino F., Tisato F., Bjornstedt M., Bindoli A., Sturaro A., Rella R., Marzano C. (2010): Cancer cell death induced by phosphine gold(I) compounds targeting thioredoxin reductase. Biochem. Pharmacol. 79, 90-101 http://dx.doi.org/10.1016/j.bcp.2009.07.023

Gladyshev V. N., Jeang K. T., Stadtman T. C. (1996): Selenocysteine, identified as the penultimate $\mathrm{C}$-terminal residue in human $\mathrm{T}$ cell thioredoxin reductase, corresponds to TGA in the human placental gene. Proc. Natl. Acad. Sci. USA 93, 6146-6151 http://dx.doi.org/10.1073/pnas.93.12.6146

Grogan T. M., Fenoglio-Prieser C., Zeheb R., Bellamy W., Frutiger Y., Vela E., Stemmerman G., Macdonald J., Richter L., Gallegos A., Powis G. (2000): Thioredoxin, a putative oncogene product, is overexpressed in gastric carcinoma and associated with increased proliferation and increased cell survival. Hum. Pathol. 31, 475-481 http://dx.doi.org/10.1053/hp.2000.6546

Gustafsson T. N., Sandalova T., Lu J., Holmgren A., Schneider G. (2007): Highresolution structures of oxidized and reduced thioredoxin reductase from Helicobacter pylori. Acta Crystallogr., Sect. D: Biol. Crystallogr. 63, 833-843 http://dx.doi.org/10.1107/S0907444907026303

Gromer S., Wissing J., Behne D., Ashman K., Schirmer R. H., Flohé L., Becker K. (1998a): A hypothesis on the catalytic mechanism of the selenoenzyme thioredoxin reductase. Biochem. J. 332, 591-592

Gromer S., Arscott L. D., Williams C. H. Jr., Schirmer R. H., Becker K. (1998b): Human placenta thioredoxin reductase. 
Isolation of the selenoenzyme, steady state kinetics, and inhibition by therapeutic gold compounds. J. Biol. Chem. 273, 20096-20101 http://dx.doi.org/10.1074/jbc.273.32.20096

Haendeler J., Hoffmann J., Tischler V., Berk B. C., Zeiher A. M., Dimmeler S. (2002): Redox regulatory and anti-apoptotic function of thioredoxin depend on S-nitrosylation at cysteine 69. Nat. Cell. Biol. 4, 743-749 http://dx.doi.org/10.1038/ncb851

Han H., Bearss D. J., Browne L. W., Calaluce R., Nagle R. B., Von Hoff D. D. (2002): Identification of differentially expressed genes in pancreatic cancer cells using cDNA microarray. Cancer Res. 62, 2890-2896

Hashemy S. I., Ungerstedt J. S., Zahedi Avval F., Holmgren A. (2006): Motexafin gadolinium, a tumor-selective drug targeting thioredoxin reductase and ribonucleotide reductase. J. Biol. Chem. 281, 10691-10697 http://dx.doi.org/10.1074/jbc.M511373200

Hirota K., Matsui M., Iwata S., Nishiyama A., Mori K., Yodoi J. (1997): AP-1 transcriptional activity is regulated by a direct association between thioredoxin and Ref-1. Proc. Natl. Acad. Sci. USA 94, 3633-3638 http://dx.doi.org/10.1073/pnas.94.8.3633

Hirt R. P., Müller S., Embley T. M., Coombs G. H. (2002): The diversity and evolution of thioredoxin reductase: new perspectives. Trends Parasitol. 18, 302-308 http://dx.doi.org/10.1016/S1471-4922(02)02293-6

Holmgren A. (1985): Thioredoxin. Annu. Rev. Biochem. 54, 237-271 http://dx.doi.org/10.1146/annurev.bi.54.070185.001321

Huber H. E., Tabor S., Richardson Ch. C. (1987): Escherichia coli thioredoxin stabilizes complexes of bacteriophage T7 DNA polymerase and primed templates. J. Biol. Chem. 262, 16224-16232

Jaeger T., Budde H., Flohe L., Menge U., Singh M., Trujillo M., Radi R. (2004): Multiple thioredoxin-mediated routes to detoxify hydroperoxides in Mycobacterium tuberculosis. Arch. Biochem. Biophys. 423, 182-191 http://dx.doi.org/10.1016/j.abb.2003.11.021

Johansson C., Lillig C. H., Holmgren A. (2004): Human mitochondrial glutaredoxin reduces S-glutathionylated proteins with high affinity accepting electrons from either glutathione or thioredoxin reductase. J. Biol. Chem. 279, 7537-7543 http://dx.doi.org/10.1074/jbc.M312719200

Lu J., Chew E.-H., Holmgren A. (2007): Targeting thioredoxin reductase is a basis for cancer therapy by arsenic trioxide. Proc. Natl. Acad. Sci. USA 104, 12288-12293 http://dx.doi.org/10.1073/pnas.0701549104

Kang J.-G., Paget M. S. B., Seok Y.-J., Hahn M.-Y., Bae J.-B., Kleanthous C. (1999): RsrA, an anti-sigma factor regulated by redox change. EMBO J. 18, 4292-4298 http://dx.doi.org/10.1093/emboj/18.15.4292

Karlenius T. Ch., Tonissen K. F. (2010): Thioredoxin and cancer: a role for thioredoxin in all states of tumor oxygenation. Cancers 2, 209-232 http://dx.doi.org/10.3390/cancers2020209

Kim Y. C., Masutani H., Yamaguchi Y., Itoh K., Yamamoto M., Yodoi J. (2001): Hemin-induced activation of the thioredoxin gene by Nrf2. A differential regulation of the antioxidant responsive element by a switch of its binding factors. J. Biol. Chem. 276, 18399-18406 http://dx.doi.org/10.1074/jbc.M100103200

Kim H. J., Chae H. Z., Kim Y. J., Kim Y. H., Hwangs T. S., Park E. M., Park Y. M. (2003): Preferential elevation of Prx I and Trx expression in lung cancer cells following hypoxia and in human lung cancer tissues. Cell. Biol. Toxicol. 19, 285-298 http://dx.doi.org/10.1023/B:CBTO.0000004952.07979.3d

Kirkpatrick D. L., Kuperus M., Dowdeswell M., Potier N., Donald L. J., Kunkel M., Berggen M., Angulo M., Powis G. (1998): Mechanisms of inhibition of the thioredoxin growth factor system by antitumor 2-imidazolyl disulfides. Biochem. Pharmacol. 55, 987-994 http://dx.doi.org/10.1016/S0006-2952(97)00597-2

Koháryová M., Kollárová M. (2008): Oxidative stress and thioredoxin system. Gen. Physiol. Biophys. 27, 71-84

Kosek D., Psenakova K., Rezabkova L., Herman P., Vecer J., Obsilova V., Obsil T. (2014). Biophysical and structural characterization of the thioredoxin-binding domain of protein kinase ASK1 and its interaction with reduced thioredoxin. J. Biol. Chem. 289, 24463-24474 http://dx.doi.org/10.1074/jbc.M114.583807

Kunkel M. W., Kirkpatrick D. L., Johnson J. I., Powis G. (1997): Cell line-directed screening assay for inhibitors of thioredoxin reductase signaling as potential anti-cancer drugs. Anticancer Drug Des. 12, 659-670

Laurent T. C., Moore E. C., Reichard P. (1964): Enzymatic synthesis of deoxyribonucleotides. IV. Isolation and characterization of thioredoxin, the hydrogen donnor from E. coli B. J. Biol. Chem. 239, 3436-3444

Lee J.-M., Johnson J.A. (2004): An important role of Nrf2-ARE pathway in the celullar defense mechanism. J. Biochem. Mol. Biol. 37, 139-143

http://dx.doi.org/10.5483/BMBRep.2004.37.2.139

Liu Z., Du Z. Y., Huang Z. S., Lee K. S., Gu L. Q. (2008): Inhibition of thioredoxin reductase by curcumin analogs. Biosci Biotechnol Biochem 72, 2214-2218 http://dx.doi.org/10.1271/bbb.80229

Lu J., Papp L. V., Fang J., Rodriguez-Nieto S., Zhivotovsky B., Holmgren A. (2006): Inhibition of mammalian thioredoxin reductase by some flavonoids: Implications for myricetin and quecetin anticancer activity. Cancer. Res 66, 4410-4418

http://dx.doi.org/10.1158/0008-5472.CAN-05-3310

Lu J., Holmgren A. (2014): The thioredoxin antioxidant system. Free Radic. Biol. Med. 66, 75-87

http://dx.doi.org/10.1016/j.freeradbiomed.2013.07.036

Luo T., Fan T., Liu Y., Rothbart M., Yu J., Zhou S., Grimm B., Luo M. (2012): Thioredoxin redox regulates ATPase activity of magnesium chelatase CHLI subunit and modulates redoxmediated signaling in tetrapyrrole biosynthesis and homeostasis of reactive oxygen species in pea plants. Plant Physiology 159, 118-130 http://dx.doi.org/10.1104/pp.112.195446

Luthman M., Holmgren A. (1982): Rat liver thioredoxin and thioredoxin reductase: purification and characterization. Biochemistry 21, 6628-6633 http://dx.doi.org/10.1021/bi00269a003 
Masutani H., Hirota K., Sasada T., Ueda-Taniguchi Y., Taniguchi Y., Sono H., Yodoi J. (1996): Transactivation of an inducible anti-oxidative stress protein, human thioredoxin by HTLV-I Tax. Immunol. Lett. 54, 67-71 http://dx.doi.org/10.1016/S0165-2478(96)02651-X

May J. M., Mendiratta S., Hill K. E., Burk R. F. (1997): Reduction of dehydroascorbate to ascorbate by the selenoenzyme thioredoxin reductase. J. Biol. Chem. 272, 22607-22610 http://dx.doi.org/10.1074/jbc.272.36.22607

Mehta M. P., Shapiro W. R., Phan S. C., Gervais R., Carrie C., Chabot P., Patchell R. A., Glantz M. J., Recht L., Langer C. et al. (2009): Motexafin gadolinium combined with prompt whole brain radiotherapy prolongs time to neurologic progression in non-small-cell lung cancer patients with brain metastases: results of a phase III trial. Int. J. Radiat. Oncol. Biol. Phys. 73, 1069-1076 http://dx.doi.org/10.1016/j.ijrobp.2008.05.068

Mirabelli C. K., Johnson R. K., Hill D. T., Faucette L. F., Girarg G. R., Kuo G. Y., Sung C. M., Crooke S. T. (1986): Correlation of the in vitro cytotoxic and in vivo antitumor activities of gold(I) coordination complexes. J. Med. Chem. 29, 218-223 http://dx.doi.org/10.1021/jm00152a009

Misra-Press A., McMillan M., Cudaback E., Qabar M., Ruan F., Nguyen M., Vaisar T., Nakanishi H., Kahn M. (2002): Identification of a novel inhibitor of the NF-kB pathway. Curr. Med. Chem. Anti Inflamm. Anti Allergy Agents 1, 29-39 http://dx.doi.org/10.2174/1568014024606566

Moi P., Chan K., Asunis I., Cao A., Kan Y. W. (1994): Isolation of NF-E2-related factor 2 (Nrf2), a NF-E2-like basic leucine zipper transcriptional activator that binds to the tandem NF-E2/ AP1 repeat of the beta-globin locus control region. PNAS 91, 9926-9930 http://dx.doi.org/10.1073/pnas.91.21.9926

Mukherjee A., Westwell A. D., Bradshaw T. D., Stevens M. F. G., Carmichael J., Martin S. G. (2005): Cytotoxic and antiangiogenic activity of AW464 (NSC 706704), a novel thioredoxin inhibitor: an in vitro study. Br. J. Cancer 92, 350-358 http://dx.doi.org/10.1038/sj.bjc.6602338

Nakamura H., De Rosa S., Roederer M., Anderson M. T., Dubs J. G., Yodoi J., Holmgren A., Herzenberg L. A. (1996): Elevation of plasma thioredoxin levels in HIV infected individuals. Int. Immunol. 8, 603-611 http://dx.doi.org/10.1093/intimm/8.4.603

Nakamura H., Vaage J., Valen G., Padilla C. A., Björnstedt M., Holmgren A. (1998): Measurements of plasma glutaredoxin and thioredoxin in healthy volunteers and during open-heart surgery. Free Radic. Biol. Med. 24, 1176-1186 http://dx.doi.org/10.1016/S0891-5849(97)00429-2

Nalvarte I., Damdimopoulos A. E., Spyrou G. (2004): Human mitochondrial thioredoxin reductase reduces cytochrome $\mathrm{c}$ and confers resistance to complex III inhibition. Free Radic. Biol. Med. 36. 1270-1278 http://dx.doi.org/10.1016/j.freeradbiomed.2004.02.072

Newton G. L., Arnold K., Price M. S., Sherrill C., Delcardayre S. B. Aharonowitz Y., Cohen G., Davies J., Fahey R. C., Davis C. (1996): Distribution of thiols in microorganisms: mycothiol is a major thiol in most actinomycetes. J. Bacteriol. 178, 1990-1995
Nishinaka Y., Masutani H., Nakamura H., Yodoi J. (2001): Regulatory roles of thioredoxin in oxidative stress-induced cellular responses. Redox Rep. 6, 289-295 http://dx.doi.org/10.1179/135100001101536427

Nunoshiba T. (1996): Two-stage gene regulation of the superoxide stress response soxRS system in Escherichia coli. Crit. Rev. Eukaryot. Gene Expr. 6, 377-389 http://dx.doi.org/10.1615/CritRevEukarGeneExpr.v6.i4.30

Paget M. S. Kang J. G., Roe J. H., Buttner M. J. (1998): $\delta^{R}$, an RNA polymerase sigma factor that modulates expression of the thioredoxin system in response to oxidative stress in Streptomyces coelicolor A3 (2). EMBO J. 17, 5776-5782 http://dx.doi.org/10.1093/emboj/17.19.5776

Paget M. S., Molle V., Cohen G., Aharonowitz Y., Buttner M. J. (2001): Defining the disulphide stress response in Streptomyces coelicolor A3(2): identification of the sigma $\mathrm{R}$ regulon. Mol. Microbiol. 42,1007-1020 http://dx.doi.org/10.1046/j.1365-2958.2001.02675.x

Pallis M., Bradshaw T. D., Westwell A. D., Grundy M., Stevens M. F. G., Russell N. (2003): Induction of apoptosis without redox catastrophe by thioredoxin-inhibitory compounds. Biochem. Pharmacol. 66, 1695-1705 http://dx.doi.org/10.1016/S0006-2952(03)00471-4

Powis G., Kirkpatrick D. L., Angulo M., Baker A. (1998): Thioredoxin redox control of cell growth and death and the effects of inhibitors. Chem. Biol. Interact. 111, 23-34 http://dx.doi.org/10.1016/S0009-2797(97)00148-8

Powis G., Mustacich D., Coon A. (2000): The role of the redox protein thioredoxin in cell growth and cancer. Free Radic. Biol. Med. 29, 312-322 http://dx.doi.org/10.1016/S0891-5849(00)00313-0

Powis G., Montfort W. R. (2001): Properties and biological activities of thioredoxins. Annu. Rev. Pharmacol. Toxicol. 41, 261-295 http://dx.doi.org/10.1146/annurev.pharmtox.41.1.261

Pieters J. (2008): Mycobacterium tuberculosis and the macrophage: maintaining a balance. Cell Host Microbe 3, 399-407 http://dx.doi.org/10.1016/j.chom.2008.05.006

Raffel J., Bhattacharyya A. K., Gallegos A., Cui H. Einspahr J. G., Alberts D. S., Powis G. (2003): Increased expression of thioredoxin-1 in human colorectal cancer is associated with decreased patient survival. J. Lab. Clin. Med. 142, 46-51 http://dx.doi.org/10.1016/S0022-2143(03)00068-4

Raman K., Yeturu K., Chandra N. (2008): targetTB: a target identification pipeline for Mycobacterium tuberculosis through an interactome, reactome and genome-scale structural analysis. BMC Syst. Biol. 2, 109 http://dx.doi.org/10.1186/1752-0509-2-109

Reott M. A., Parker A. C., Rocha E. R., Smith C. J. (2009): Thioredoxins in redox maintenance and survival during oxidative stress of Bacteroides fragilis. J. Bacteriol. 191, 3384-3391 http://dx.doi.org/10.1128/JB.01665-08

Rich E. A., Torres M., Sada E., Finegan C. K., Hamilton B. D., Toossi Z. (1997): Mycobacterium tuberculosis (MTB)-stimulated production of nitric oxide by human alveolar macrophages and relationship of nitric oxide production to growth inhibition of MTB. Tuber. Lung Dis. 78, 247-255 http://dx.doi.org/10.1016/S0962-8479(97)90005-8 
Rigobello M. P., Messori L., Marcon G., Agostina Cinellu M., Bragadin M., Folda A., Scutari G., Bindoli A. (2004): Gold complexes inhibit mitochondrial thioredoxin reductase: consequences on mitochondrial functions. J. Inorg. Biochem. 98, 1634-1641 http://dx.doi.org/10.1016/j.jinorgbio.2004.04.020

Rocha E. R., Tzianabos A. O., Smith C. J. (2007): Thioredoxin reductase is essential for thiol/disulfide redox control and oxidative stress survival of the anaerobe Bacteroides fragilis. J. Bacteriol. 189, 8015-8023 http://dx.doi.org/10.1128/JB.00714-07

Ross J. A., Kasum C. M. (2002): Dietary flavonoids: bioavailability, metabolic effects, and safety. Annu. Rev. Nutr. 22, 19-34 http://dx.doi.org/10.1146/annurev.nutr.22.111401.144957

Rubartelli A., Bonifaci N., Sitia R. (1995): High rates of thioredoxin secretion correlate with growth arrest in hepatoma cells. Cancer Res. 55, 675-680

Ryan K. J., Ray C. G (2004): Sherris Medical Microbiology (4th ed.). McGraw Hill

Saito I., Shimuta M., Terauchi K., Tsubota K., Yodoi J., Miyasaka N. (1996): Increased expression of human thioredoxin/adult T cell leukemia-derived factor in Sjogren's syndrome. Arthritis Rheum. 39, 773-782 http://dx.doi.org/10.1002/art.1780390509

Saitoh M., Nishitoh H., Fujii M., Takeda K., Tobiume K., Sawada Y., Kawabata M., Miyazono K., Ichijo H. (1998): Mammalian thioredoxin is a direct inhibitor of apoptosis signal-regulating kinase (ASK) 1. EMBO J. 17, 2596-2606 http://dx.doi.org/10.1093/emboj/17.9.2596

Sasada T., Iwata S., Sato N., Kitaoka Y., Hirota K., Nakamura K., Nishiyama A., Taniguchi Y., Takabayashi A., Yodoi J. (1996): Redox control of resistance to cis-diamminedichloroplatinum (II) (CDDP): protective effect of human thioredoxin against CDDP-induced cytotoxicity. J. Clin. Invest. 97, 2268-2276 http://dx.doi.org/10.1172/JCI118668

Sasada T., Nakamura H., Ueda S., Sato N., Kitaoka Y., Gon Y., Takabayashi A., Spyrou G., Holmgren A., Yodoi J. (1999): Possible involvement of thioredoxin reductase as well as thioredoxin in cellular sensitivity to cis-diamminedichloroplatinum (II). Free Radic. Biol. Med. 27, 504-514 http://dx.doi.org/10.1016/S0891-5849(99)00101-X

Selenius M., Hedman M., Brodin D., Gandin V., Rigobello M. P., Flygare J., Marzano C. H., Bindoli A., Brodin O., Bjornstedt M., Fernandes A. P. (2012): J. Cell. Mol. Med. 16, 1593-1605 http://dx.doi.org/10.1111/j.1582-4934.2011.01469.x

Scharf C., Riethdorf S., Ernst H., Engelmann S., Volker U., Hecker M. (1998): Thioredoxin is an essential protein induced by multiple stresses in Bacillus subtilis. J. Bacteriol. 180, 1869-1877

Schweizer U., Brauer A. U., Kohrle J., Nitsch R., Savaskan N. E. (2004): Selenium and brain function: a poorly recognized liaison. Brain Res. Rev. 45, 164-178 http://dx.doi.org/10.1016/j.brainresrev.2004.03.004

Shaw C. F. (1999): Gold-based therapeutic agents. Chem. Rev. 99, 2589-2600 http://dx.doi.org/10.1021/cr980431o

Shinnick T. M., King H., Quinn F. D. (1995): Molecular biology, virulence, and pathogenicity of mycobacteria. Am. J. Med. Sci. 309, 92-98 http://dx.doi.org/10.1097/00000441-199502000-00008
Smart D., Ortiz K., Mattson D., Bradbury C. M., Bisht K. S., Sieck L. K., Brechbiel M. W., Gius D. (2004): Thioredoxin reductase as a potential molecular target for anticancer agents that induce oxidative stress. Cancer Res. 64, 6716-6724 http://dx.doi.org/10.1158/0008-5472.CAN-03-3990

Sorrentino F., Karioti A., Gratteri P., Rigobello M. P., Scutari G., Messori L., Bindoli A., Chioccioli M., Gabbiani Ch., Bergonzi M. C., Bilia A. R. (2011): Hypericins and thioredoxin reductase: Biochemical and docking studies disclose the molecular basis for effective inhibition by naphthodianthrones. Bioorg. Med. Chem. 19, 631-641 http://dx.doi.org/10.1016/j.bmc.2010.10.045

Söderberg A., Sahaf B., Rosn A. (2000): Thioredoxin reductase, a redox-active selenoprotein, is secreted by normal and neoplastic cells: presence in human plasma. Cancer Res. 60, 2281-2289

Sumida S., Nakamura H., Yodoi J. (2004): Thioredoxin induction of peripheral blood mononuclear cells in mice in response to a single bout of swimming exercise. Gen. Physiol. Biophys. 23, 241-249

Sun Q. A., Su D., Novoselov S. V., Carlson B. A., Hatfield D. L., Gladyshev V. N. (2005): Reaction mechanism and regulation of mammalian thioredoxin/glutathione reductase. Biochemistry 44, 14528-14537 http://dx.doi.org/10.1021/bi051321w

Sund C. J., Rocha E. R., Tzianabos A. O.,Wells W. G., Gee J. M., Reott M. A., O'Rourke D. P., Smith C. J. (2008): The Bacteroides fragilis transcriptome response to oxygen and $\mathrm{H} 2 \mathrm{O} 2$ : the role of OxyR and its effect on survival and virulence. Mol. Microbiol. 67, 129-142 http://dx.doi.org/10.1111/j.1365-2958.2007.06031.x

Štefanková P., Kollárová M., Barák I. (2005): Thioredoxin - structural and functional complexity. Gen. Physiol. Biophys. 24, 3-11

Tally F. P., Jacobus N. V., Bartlett J. G., Gorbach S. L. (1975): In vitro activity of penicillins against anaerobes. Antimicrob. Agents Chemother. 7, 413-414

http://dx.doi.org/10.1128/AAC.7.4.413

Tamura T., Stadtman T. C. (1996): A new selenoprotein from human lung adenocarcinoma cells: purification, properties, and thioredoxin reductase activity. Proc. Natl. Acad. Sci. USA 93, 1006-1011 http://dx.doi.org/10.1073/pnas.93.3.1006

Tanudji M., Hevi S., Chuck S. L. (2003): The nonclassic secretion of thioredoxin is not sensitive to redox state. Am. J. Physiol. Cell Physiol. 284, C1272-1279

http://dx.doi.org/10.1152/ajpcell.00521.2002

Tao K., Fujita N., Ishihama A. (1993): Involvement of the RNA polymerase alpha subunit C-terminal region in co-operative interaction and transcriptional activation with OxyR protein. Mol. Microbiol. 7, 859-864 http://dx.doi.org/10.1111/j.1365-2958.1993.tb01176.x

Tao L., Jiao X., Gao E., Lau W. B., Yuan Y., Lopez B., Christopher T., Ramachandrarao S. P., Williams W., Southan G., Sharma K., Koch W., Ma X. L. (2006): Nitrative inactivation of thioredoxin-1 and its role in postischemic myocardial apoptosis. Circulation 114, 1395-1402 http://dx.doi.org/10.1161/CIRCULATIONAHA.106.625061 
Tonissen K. F., Di Trapani G. (2009): Thioredoxin system inhibitors as mediators of apoptosis for cancer therapy. Mol. Nutr. Food Res. 53, 87-103 http://dx.doi.org/10.1002/mnfr.200700492

Tsang M. L., Schiff J. A. (1976): Sulfate-reducing pathway in Escherichia coli involving bound intermediates. J. Bacteriol. 125, 923-933

Uziel O., Borovok I., Schreiber R., Cohen G., Aharonowitz Y. (2004): Transcriptional regulation of the Staphylococcus aureus thioredoxin and thioredoxin reductase genes in response to oxygen and disulfide stress. J. Bacteriol. 186, 326-334 http://dx.doi.org/10.1128/JB.186.2.326-334.2004

Varsik P., Buranova D., Kollar B., Fedor-Freybergh P. G. (2006): Metabolic stroke in the three years old boy as acosequence of metabolic derangement. A case report of recidiving Reye's-like syndrome. Neuro. Endocrinol. Lett. 27, 13-15

Wagner C., Sudati J. H., Nogueira C. W., Rocha J. B. (2010): In vivo and in vitro inhibition of mice thioredoxin reductase by methylmercury. Biometals 23, 1171-1177 http://dx.doi.org/10.1007/s10534-010-9367-4

Watson W. H., Jones D. P. (2003): Oxidation of nuclear thioredoxin during oxidative stress. FEBS Lett. 543, 144-147 http://dx.doi.org/10.1016/S0014-5793(03)00430-7

Welsh S. J., Williams R. R., Birmingham A., Newman D. J., Kirkpatrick D. L., Powis G. (2003): The thioredoxin redox inhibitors 1-methylpropyl 2-imidazolyl disulfide and pleurotin inhibit hypoxia-induced factor $1 \alpha$ and vascular endothelial growth factor formation. Mol. Cancer Ther. 2, 235-243

Wieles B., van Noort J., Drijfhout J. W., Offringa R., Holmgren A., Ottenhoff T. H. (1995): Purification and functional analysis of the Mycobacterium leprae thioredoxin/thioredoxin reductase hybrid protein. J. Biol. Chem. 270, 25604-25606 http://dx.doi.org/10.1074/jbc.270.43.25604

Williams C. H. Jr. (1992): Lipoamide dehydrogenase, glutathione reductase, thioredoxin reductase, and mercuric ion reductase a family of flavoenzyme transhydrogenases. In: Chemistry and Biochemistry of Flavoenzymes. (Ed. F.Müller), pp. 121-211, CRC Press, Boca Raton

Williams C. H. Jr., Arscott L. D., Müller S., Lennon B. W., Ludwig M. L., Wang P. F., Veine D. M., Becker K. (2000): Thioredoxin reductase. Two models of catalysis have evolved. Eur. J. Biochem. 267, 6110-6117 http://dx.doi.org/10.1046/j.1432-1327.2000.01702.x

Williams R. J., Spencer J. P., Rice-Evans C. (2004): Flavonoids: antioxidants or signalling molecules? Free Radic. Biol. Med. 36, 838-849 http://dx.doi.org/10.1016/j.freeradbiomed.2004.01.001

Wipf P., Hopkins T. D., Jung J.-K., Rodriguez S., Birmingham A., Southwick E. C., Lazo J. S., Powis G. (2001): New inhibitors of the thioredoxin-thioredoxin reductase system based on a napthoquinone spiroketal natural product lead. Bioorg. Med. Chem. Lett. 11, 2637-2641

http://dx.doi.org/10.1016/S0960-894X(01)00525-X
Witte A. B., Anestal K., Jerremalm E., Ehrsson H., Arner E. S. (2005): Inhibition of thioredoxin reductase but not glutathione reductase by the major classess of alkylating and platinumcontaining anticancer compounds. Free Radic. Biol. Med. 39, 696-703 http://dx.doi.org/10.1016/j.freeradbiomed.2005.04.025

Xia L., Nordman T., Olsson J. M., Damdimopoulos A., BjorkhemBergman L., Nalvarte I., Eriksson L. C., Arner E. S., Spyrou G., Bjornstedt M. (2003): The mammalian cytosolic selenoenzyme thioredoxin reductase reduces ubiquinone. A novel mechanism for defense against oxidative stress. J. Biol. Chem. 278, 2141-2146 http://dx.doi.org/10.1074/jbc.M210456200

Yang C. S., Landau J. M., Huang M. T., Newmark H. L. (2001): Inhibition of carcinogenesis by dietary polyphenolic compounds. Annu. Rev. Nutr. 21, 381-406 http://dx.doi.org/10.1146/annurev.nutr.21.1.381

Yang L., Yijing 1., Shenghui Y., Gusen Z. (2012): Recent advanced in development of thioredoxin reductase inhibitors as anticancer agents. Curr. Drug Targets 13, 1432-1444 http://dx.doi.org/10.2174/138945012803530224

Yokomizo A., Ono M., Nanri H., Makino Y., Ohga T., Wada M., Okamoto T., Yodoi J., Kuwano M., Kohno K. (1995): Cellular levels of thioredoxin associated with drug sensitivity to cisplatin, mitomycin C, doxorubicin, and etoposide. Cancer Research 55, 4293-4296

Yoshida S., Katoh T., Tetsuka T., Uno K., Matsui N., Okamoto T. (1999): Involvement of thioredoxin in rheumatoid arthritis: its costimulatory roles in the TNF-alpha-induced production of IL- 6 and IL-8 from cultured synovial fibroblasts. J. Immunol. $163,351-358$

Young L. D., Darryl Y., Bateman R. M., Brock G. B. (2004): Oxidative stress and antioxidant therapy: their impact in diabetesassociated erectile dysfunction. J. Androl. 25, 830-836

Yuan Y., Jiao X., Lau W. B., Wang Y., Christopher T. A., Lopez B. L., RamachandraRao S. P., Tao L., Ma X.-L. (2010): Thioredoxin glycation: a novel posttranslational modification that inhibits its antioxidant and organ protective actions. Free Radic. Biol. Med. 49, 332-338 http://dx.doi.org/10.1016/j.freeradbiomed.2010.04.017

Zhang Y. Z., Gould K. L., Dunbrack R. L. Jr., Cheng H., Roder H., Golemis E. A. (1999): The evolutionarily conserved Dim1 protein defines a novel branch of the thioredoxin fold superfamily. Physiol. Genomics 1, 109-118

Zhong L., Du Z. Y., Huang Z. S., Lee K. L., Gu L. Q. (2008): Inhibition of thioredoxin reductase by curcumin alanogs. Biosci. Biotechnol. Biochem. 72, 2214-2218 http://dx.doi.org/10.1271/bbb.80229

Received: October 22, 2014

Final version accepted: February 9, 2015

First published online: April 30, 2015 